\title{
IRRIGAÇÃO DO CAFEEIRO: abertura de flores e produtividade de café
}

Maurício Cezar Resende LEITE JR ${ }^{1}$

Manoel Alves de FARIA ${ }^{2}$

${ }^{1}$ Professor Tempo integral na Universidade Vale do Rio Verde (UninCor), Doutor em Recursos Hídricos em Sistemas

Agrícolas. mauricio_cezar_leite@yahoo.com.br

2Professor dedicação exclusiva na Universidade Federal de Lavras, Doutor em Engenharia Agrícola.

Recebido em: 05/01/2016 - Aprovado em: 24/04/2016 - Disponibilizado em: 30/07/2016

\begin{abstract}
RESUMO: Várias técnicas de submissão da cultura cafeeira a restrição hídrica, tem sido pesquisadas nas últimas décadas, logo, o objetivo foi testar manejos de irrigação com aplicação de diferentes disponibilidades hídricas na lavoura cafeeira, buscando melhor sincronismo da florada e maior produtividade. O experimento foi instalado no município de Lavras/MG, numa lavoura com cafeeiro Acaiá MG-1474, implantado num espaçamento semi-adensado de 3,0 x 0,6 m. O delineamento experimental usado foi o de blocos casualizados com 5 tratamentos e 4 repetições. Os tratamentos foram: A = Sem irrigação; B = Irrigação o ano todo sempre que a planta consumiu 75\% da água disponível; $\mathrm{C}=$ Irrigação o ano todo sempre que a planta consumiu $25 \%$ da água disponível; $\mathrm{D}=$ Irrigação o ano todo se em jan / fev / mar / jul / out / nov / dez a planta consumiu 25\% da água disponível e em abr / mai / jun / ago / set se a planta consumiu 75\% da água disponível e E = Irrigação em Abr / Mai / Jun / Ago / Set se a planta consumiu 25\% da água disponível. Os tratamentos de irrigação não proporcionaram um sincronismo diferenciado na floração do cafeeiro, e a quebra de dormência dos botões florais parece ter ocorrido devido fatores meteorológicos. Nas condições em que se encontrava a lavoura, não foi possível impor uma restrição hídrica capaz de induzir sincronismo de abertura de flores na planta, através dos manejos de irrigação, por ocorrência de volumes de precipitações pluviais antes que seja atingindo uma restrição hídrica relatado por alguns autores como sendo o ideal.
\end{abstract}

Palavras- chave: Manejo de irrigação. Indução floral. Vingamento de flores. Floração. Maturação.

\section{COFFEE IRRIGATION: flowers opening and coffee productivity}

\begin{abstract}
Several Submission Techniques the Coffee Culture of fluid restriction, HAS BEEN surveyed in recent decades, logo, the goal was Test managements Irrigation with Different Application Availability in water Coffee farming, seeking better timing Florada and Increased Productivity. The experiment was conducted in Lavras / MG, a crop with coffee Acaiá MG-1474, deployed in a semi-dense spacing of 3.0 x $0.6 \mathrm{~m}$. The experimental design used was a randomized block design with 5 treatments and 4 repetitions. Treatments OS Were: $\mathrm{A}=$ No Irrigation; $\mathrm{B}=$ Irrigation ALL the year always That plant consumed $75 \%$ of available water; $\mathrm{C}=$ Irrigation ALL the year always That plant consumed $25 \%$ of available water; D = irrigation throughout the year in Jan / Feb / Mar / Jul / Oct / Nov / Dec of a plant consumed 25\% of the available water and in Apr / May / Jun / Aug / Sep to a plant consumed 75\% of Available Water and E = Irrigation in Apr / May / Jun / Aug / Sep to a plant consumed 25\% of the available water. The irrigation treatments NOT provided hum different timing in coffee flowering and dormancy breaking of buds seems to have occurred due to weather factors. The conditions it was in farming, not possible was a impose Fluid restriction Able to induce flowers opening timing in the plant, through the irrigation managements, For Instance volumes of rainfall before it be reaching a water restriction reported by some authors Like Being ideal.
\end{abstract}

Key-words: Irrigation Management. floral induction. Fruit set of flowers. Flowering. Maturation.

\section{INTRODUÇÃO}

O mercado mundial do café movimenta anualmente bilhões de dólares, situando esta cultura como uma das mais importantes do planeta e despertando cada vez mais o interesse dos agricultores em aumentar a produtividade e reduzir os custos de produção. 
O cafeeiro possui gemas florais seriadas, se desenvolvendo e chegando à maturação em épocas distintas, o que, sob condições normais, leva à ocorrência de floradas também em série, ou seja, em períodos sucessivos, sendo normal 2 a 3 floradas principais, que ocorrem de outubro a dezembro (MATIELLO 2006, p. 29-30). Quando o período de pós colheita é bem seco, vários grupos (séries) de gemas florais chegam à maturação e logo entram em dormência de forma mais uniforme, levando a floradas e, conseqüente frutificação e maturação também mais homogêneas, o que facilita a colheita e a qualidade do café (MATIELLO 2006, p. 29-30).

Guerra et al. (2007) estabeleceram o período e a magnitude do estresse hídrico para sincronizar o desenvolvimento dos botões florais e obter uniformização da florada em lavouras comerciais do oeste da Bahia e em área experimental da Embrapa Cerrado. Basicamente, o que os autores propuseram foi a suspensão das irrigações em 24 de junho e o retorno das aplicações de água entre 2 e 4 de setembro, com, aproximadamente, 70 dias sem irrigação. Dentre os pontos positivos relatados por estes autores, pode-se citar a redução significativa do consumo de água e energia, resultante da prática do manejo de irrigação e do período do estresse hídrico e a redução das operações de máquinas na colheita, da ordem de $40 \%$. Houve significativa redução do custo da atividade e maximização da produção de cafés especiais.

A suspensão de irrigações para floração, estresse hídrico ou simplesmente déficit hídrico para quebra de dormência e uniformização ou sincronização da florada é assunto bastante discutido na atualidade, gerando muita polêmica, sem chegar a um denominador comum. Em face de resultados contraditórios, em função notadamente das diferenças climáticas (temperatura e umidade do ar) de cada região cafeeira e de cada ano em cada região, bem como das condições da lavoura, quanto a sua idade, espaçamento, espécie e variedade (SANTINATO; FERNANDES; FERNANDES, 2008). De maneira geral, recomenda-se o uso da aplicação do déficit hídrico imitando-se a natureza, sendo em regiões frias 45-60 dias, em regiões de temperaturas médias 30-45 dias e quentes até no máximo de 30 dias antes da floração que irá variar de ano para ano (SANTINATO; FERNANDES; FERNANDES, 2008).

No entanto, as plantas de café sob déficit hídrico, têm apresentado desfolhas acentuadas, conduzindo a floradas uniformes, mas com prováveis perdas de produção (MATIELLO 2008, p.37). Têm-se, assim, resultados bons com a aplicação de déficit hídrico em relação à uniformização da floração, mas que precisam mais trabalhos de pesquisa envolvendo o assunto (MATIELLO 2006). 
Tais informações podem viabilizar o desenvolvimento de práticas que auxiliem o agricultor a planejar e utilizar a água de irrigação eficientemente para o aumento da produção e qualidade do café (GUERRA et al. 2007).

A racionalização da exploração agrícola a caminho da sustentabilidade e a incorporação de novas tecnologias pela cafeicultura tornam-se necessárias no momento competitivo que está sendo imposto ao agricultor, exigindo o conhecimento dos principais fatores relacionados à produção. Dentre estes fatores, a irrigação é de fundamental importância, com destaque na recuperação de lavouras e garantia de produção mesmo em períodos de veranicos.

Este trabalho teve como objetivo principal testar manejos de irrigação com aplicação de diferentes disponibilidades hídricas na lavoura cafeeira, buscando melhor sincronismo da florada com conseqüente uniformização da maturação dos frutos, com o intuito de obter maior produtividade, melhor qualidade do café produzido e economia na colheita.

\section{MATERIAL E MÉTODOS}

2.1 Área experimental, cultura, delineamento experimental e tratamentos

O experimento foi instalado no Departamento de Engenharia da Universidade
Federal de Lavras (UFLA), no município de Lavras - MG. O clima da região, segundo a classificação de Koppen, é do tipo Cwa, caracterizado por uma estação seca entre abril e setembro e uma estação chuvosa de outubro a março. A precipitação e a temperatura média anual são de $1.460 \mathrm{~mm}$ e $20,4^{\circ} \mathrm{C}$, respectivamente (DANTAS; CARVALHO; FERREIRA, 2007). O solo da área é classificado como Latossolo Vermelho Distroférrico. A lavoura cafeeira foi implantada em março de 1997 e recepada em outubro de 2004. A cultivar em estudo foi a Acaiá MG-1474 plantada no espaçamento 3,0 $\mathrm{m}$ entre linhas e 0,6 $\mathrm{m}$ entre plantas. $\mathrm{O}$ delineamento experimental foi o de blocos casualizados, com quatro repetições e cinco tratamentos. Os tratamentos de irrigação utilizados durante o ano, foram: $\mathrm{A}=$ Sem irrigação (testemunha); B = Irrigação o ano todo, sempre que a planta consumiu $75 \%$ da água disponível na camada de $0-20 \mathrm{~cm} ; \mathrm{C}=$ Irrigação o ano todo, sempre que a planta consumiu $25 \%$ da água disponível na camada de $0-20 \mathrm{~cm} ; \mathrm{D}=$ Irrigação o ano todo sendo que: Nos meses: jan / fev / mar / jul / out / nov / dez $\rightarrow$ foi irrigado no momento que a planta consumiu $25 \%$ da água disponível na camada de 0-20cm e nos meses: abr / mai / jun / ago / set $\rightarrow$ foi irrigado no momento em que a planta consumiu $75 \%$ da água disponível na camada de 0-20cm; E = Irrigação somente nos meses abr / mai / jun / ago / set sempre que a 
planta consumiu $25 \%$ da água disponível na camada de $0-20 \mathrm{~cm}$.

Os dados climáticos de precipitação pluvial e temperatura média diária, foram obtidos da estação climatológica principal de Lavras (ECP), localizada no campus da UFLA, à distância de $570 \mathrm{~m}$ do local do experimento, pertencente ao $5^{\circ}$ Distrito de Meteorologia, em convênio da UFLA com o Instituto Nacional de Meteorologia (INMET).

\subsection{Avaliação de floração, colheita e produtividade}

Para as avaliações de florescimento, no ano de 2006, foram marcados e numerados o primeiro par de ramo plagiotrópico de duas plantas de cada parcela, e nos anos 2007, 2008 e 2009 foram marcados um par de ramo plagiotrópico do terço médio de duas plantas de cada parcela. Foram realizadas, avaliações durante todo o período de florescimento do cafeeiro nos ramos marcados para quantificar as características: $\mathrm{n}^{\mathrm{o}}$ de ramificações secundárias; $\mathrm{n}^{\mathrm{o}}$ de botões florais e $\mathrm{n}^{\mathrm{o}}$ de flores através de contagens realizadas a partir do mês de setembro de cada ano (2006, 2007, 2008, e 2009), sendo estas avaliações realizadas a cada 7 dias ou de acordo a freqüência que ocorriam as floradas, com inicio em setembro, no momento que houve indícios de início de floração e término ao final do período de abertura de flores. $\mathrm{O}$ que determinou o fim da avaliação de florescimento foi a não ocorrência de flores em nenhum ramo marcado por seis contagens consecutivas. Para avaliação da taxa de vingamento de flores foi realizada a contagem dos frutos estabelecidos nos ramos préestabelecidos para contagem de flores, no momento da colheita de cada safra. A colheita dos frutos foi de forma manual (derriça sobre "pano"). Após a derriça, obteve-se o volume e o peso de cada parcela e separou-se uma amostra de 10 litros de frutos de cada parcela, a qual foi colocada, em saco plástico tipo rede, para secagem. Depois da secagem o café foi beneficiado e relacionado com os dados da parcela para posterior determinação de rendimento e produtividade.

\section{RESULTADOS E DISCUSSÃO}

\subsection{Confronto dos dados climáticos com as avaliações de floração}

Ao se analisar a abertura floral do cafeeiro, deve-se tomar o cuidado de estar relacionando a antese floral a fenômenos climáticos, visto que, este fenômeno é diretamente relacionado aos parâmetros de precipitações pluviais, temperatura, umidade relativa e vento. A partir desse confronto é possível verificar se houve influência dos manejos de irrigação na abertura floral.

Os dados apresentados na Figura 1/2006, precipitações pluviais e temperaturas 
médias, correspondem ao período de agosto a dezembro/2006, englobando o período de floração do cafeeiro, que segundo Matiello (2006) no cafeeiro é normal a ocorrência de 2 a 3 floradas principais, entre outubro e dezembro.

No ano de 2006, a abertura floral iniciou no dia 19/09/2006 em todos os tratamentos, sendo que os tratamentos, D com 99 flores e B com 56 flores apresentaram a maior e menor emissão de flores conforme Figura 2/2006. Essa abertura floral ocorreu após precipitações pluviais no final de agosto e inicio de setembro, perfazendo um volume total de 43,1 mm, juntamente com uma queda de temperatura de $5,1{ }^{\circ} \mathrm{C}$ entre os dias 4 e 6 de setembro/2006; podendo ter proporcionado a quebra de dormência dos botões florais para todos os tratamentos.

Figura 1 - Valores médios das temperaturas diárias e das precipitações pluviais nos períodos de agosto a dezembro dos anos 2006, 2007, 2008 e 2009. UFLA, Lavras-MG/ 2011.

\section{6}

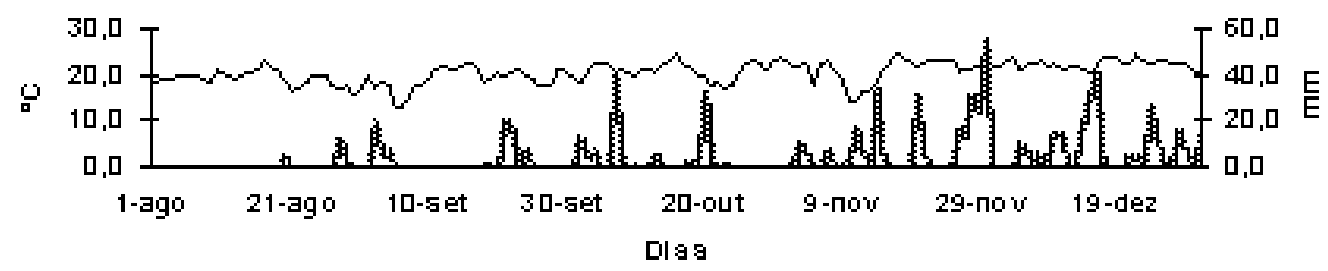

2007

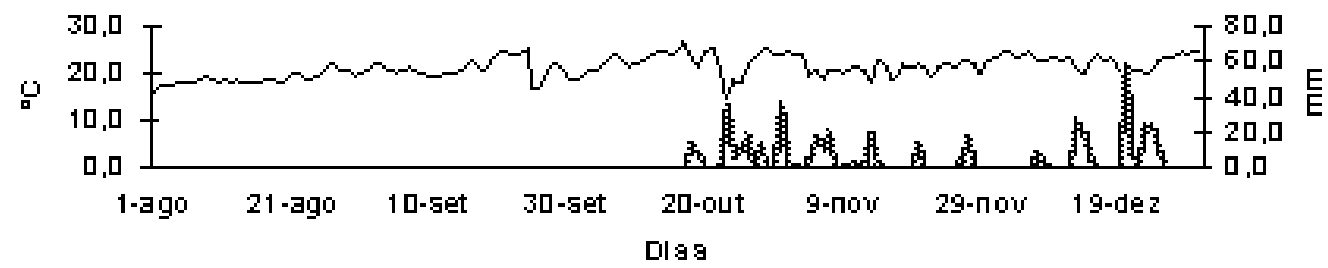

2008

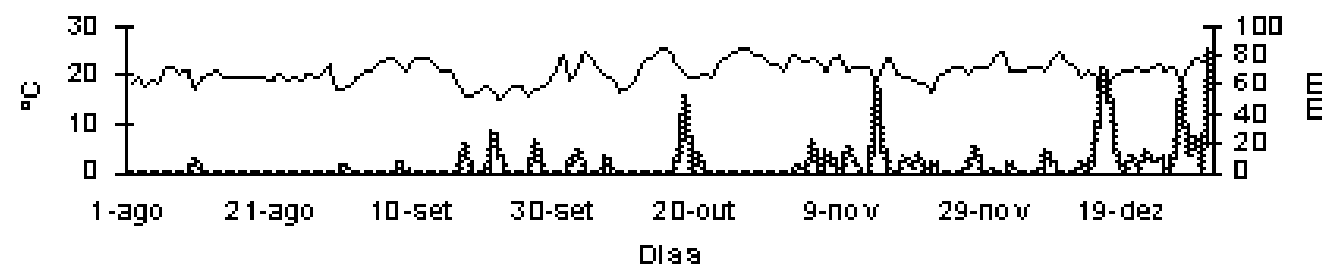




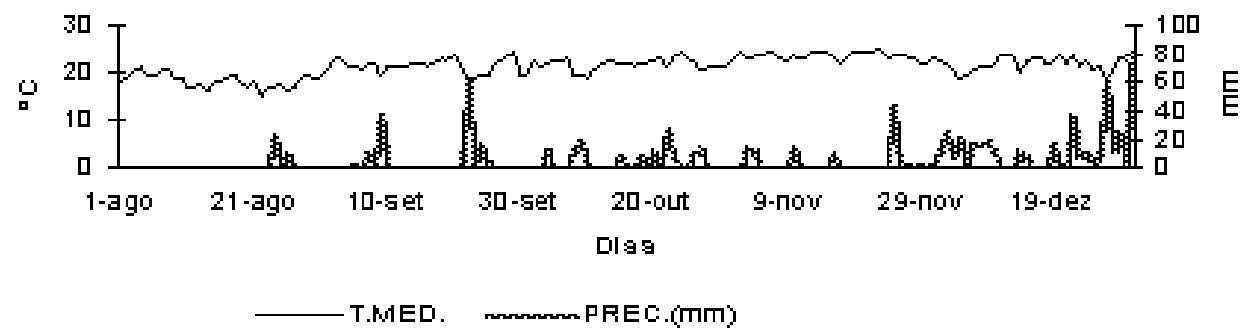

Fonte: Próprio autor.

Figura 2 - Número de flores contadas nos ramos plagiotrópicos marcados nos anos 2006, 2007, 2008 e 2009 , em função dos manejos de irrigação. UFLA, Lavras-MG/ 2011.

\section{F lorą̧ão 2006}

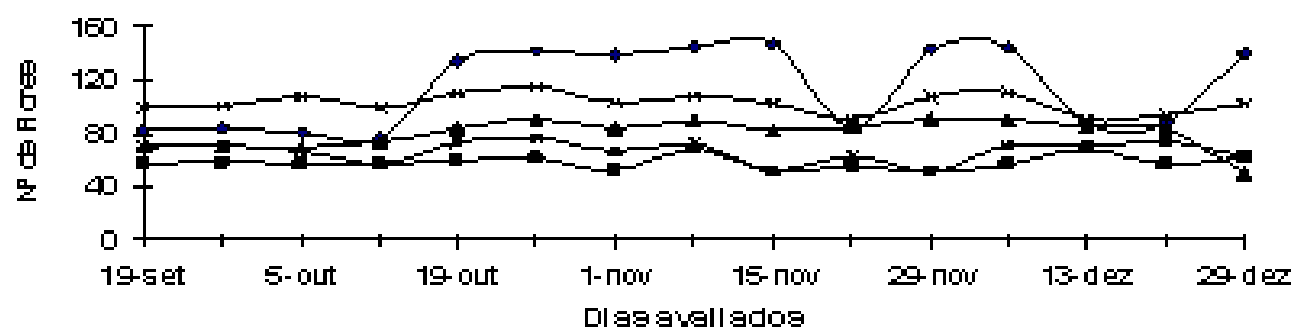

Floraqua 2007

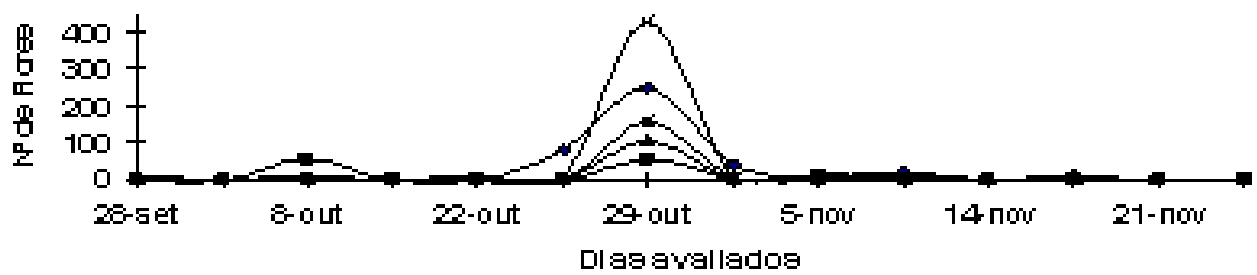

F loraq̣ão 2008

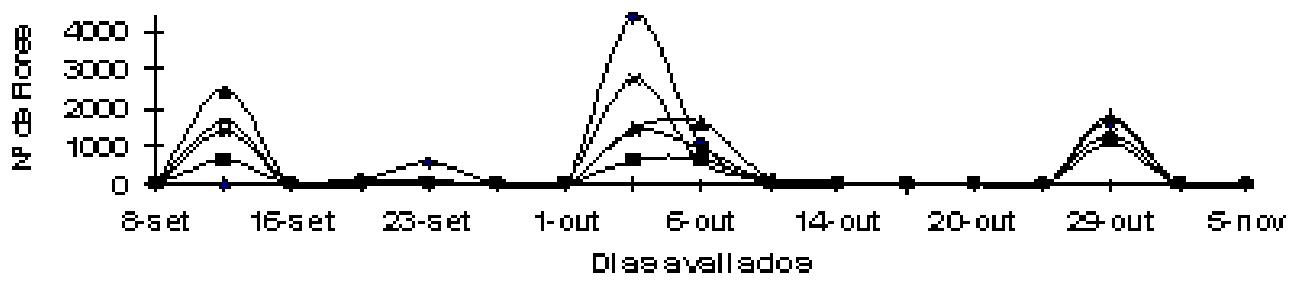




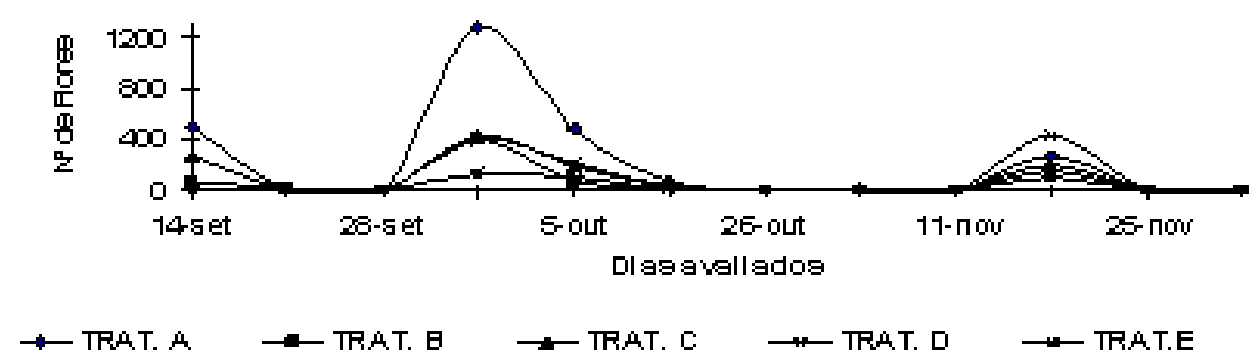

Fonte: Próprio autor.

Nos ramos plagiotrópicos marcados houve ocorrência de abertura de flores até o dia 29 de dezembro, com um intervalo médio de 7 dias entre cada avaliação. Todos os tratamentos irrigados apresentaram semelhança entre a emissão de flores, onde observou a ocorrência de várias floradas, não tendo uma data específica em que o número de flores fosse superior às demais avaliações realizadas no período para cada tratamento. Já o tratamento A (sem irrigação) apresentou em 8 avaliações um maior número de flores em relação às outras 7 avaliações realizadas conforme Figura 2/2006, concentrando entre os dias $19 / 10$ a $15 / 11,29 / 11,16 / 12$ e $29 / 12$ representando $66 \%$ do número total de flores emitidas por esse tratamento.

Esse aumento na abertura floral do tratamento A, pode ter sido influenciado por volumes de precipitações de 38 e $32 \mathrm{~mm}$ ocorridos nos dia $07 / 10$ e $20 / 10$ respectivamente, proporcionando maior umidade no solo do tratamento sem irrigação. O mesmo ocorreu nos demais "picos" de abertura de flores, que estavam sempre relacionados a eventos de precipitações antecedentes a antese em torno de 10 dias, juntamente com quedas de temperaturas.

No ano de 2007, o período considerado chuvoso na região se mostrou atípico, sendo que as precipitações iniciaram mais tardiamente, com o primeiro registro de precipitação de $11,8 \mathrm{~mm}$ no dia 18/10/2007 (Figura 1/2007). Nesse ano foi proporcionado uma restrição hídrica maior no tratamento A e no tratamento $E$ que teve suas irrigações suspensas no mês de setembro. Matiello (2006) relatam que a melhor forma de induzir a floração uniforme em cafeeiros é por meio da redução da quantidade de água, no período de julho/agosto, sem deixar os cafeeiros murcharem. Tal constatação reforça a necessidade do conhecimento da influência dos elementos meteorológicos no florescimento para o manejo da cultura do cafeeiro, principalmente em condições irrigadas.

Analisando as datas de ocorrência de flores e confrontando com os dados meteorológicos registrados, observam-se fatos 
importantes na ocorrência de abertura floral. Todos os tratamentos irrigados apresentaram antese floral no dia 08/10/2007 (Figura 2/2007), como a umidade do solo não era um fator limitante a abertura floral, suspeita-se que a ocorrência dessa emissão de flores foi devido a uma queda de temperatura de $9{ }^{\circ} \mathrm{C}$ entre os dias 24 e 26 de setembro/2007, passando de uma média diária de $25,7^{\circ} \mathrm{C}$ para $16,7^{\circ} \mathrm{C}$. Essa abertura floral correspondeu a $44 \%$ do total de flores emitidas pelo tratamento $\mathrm{B}$, sendo que, a porcentagem do número de flores abertas não foi representativa para os demais tratamentos irrigados. Na figura 2/2007 observa-se um "pico" no número de flores abertas em todos os tratamentos, no dia 29/10/2007, influenciada pelo inicio das precipitações, no dia 18/10 comentado anteriormente. Nessa data de avaliação especifica, obteve-se uma porcentagem de 59, 47, 76, 90, 84 do número total de flores emitidas respectivamente, nos tratamentos A, B, C, D e E. Nesse ano, observou-se a ocorrência de 2 floradas no tratamento B somando $91 \%$ do total de flores emitidas e um maior sincronismo na abertura floral dos tratamentos C, D e E. Essa maior uniformidade de floração não pode ser explicada pela influência dos tratamentos de irrigação.

Na Figura 1/2008 estão registrados os dados de precipitações e temperaturas médias, para o período que compreende a fase reprodutiva na fenologia cafeeira. Nesse ano de 2008 houve uma distribuição normal das precipitações, iniciadas de maneira mais freqüente no dia 14/09/2008, tendo ocorrido pequenos volumes de precipitações no mês de agosto/2008, não permitindo elevada restrição de água para a planta cafeeira. Em trabalho com mesmo objetivo, os autores buscaram a uniformização da floração do cafeeiro em Patrocínio, MG e concluíram não ser possível uniformizar a florada em uma única data por não conseguirem abaixar o potencial de água na folha na antemanhã e, portanto, não sincronizar um porcentual elevado de botões florais no estádio 4 , antes da primeira chuva que desencadeou o processo de floração (BONFIM NETO et al., 2007).

A primeira avaliação de floração foi realizada no dia 08/09/2008, sendo que só houve flores nos tratamento irrigados, na avaliação seguinte no dia 12/09/2008 (Figura 2/2008), encontrou flores somente nos tratamentos irrigados com números mais representativos em relação ao total, mostrando que a baixa umidade no solo, não permitiu a quebra de dormência dos botões florais para o tratamento A (sem irrigação). O tratamento A apresentou sua primeira florada representativa no dia 23/09/2009, onde até essa data teve um somatório de $80,6 \mathrm{~mm}$ no volume de precipitações, proporcionando assim umidade no solo satisfatória para que ocorresse a quebra de dormência dos botões florais no tratamento sem irrigação. Nas avaliações dos dias 3 e 6 de outubro/2008, todos os 
tratamentos apresentaram florada, sendo que os tratamentos A, B, C, D e E apresentaram respectivamente $70,41,41,47$ e $45 \%$ do total de flores emitidas, demonstrando que o tratamento A apresenta-se com maior sincronismo de floração. No dia 29/10/2008, foi a ultima avaliação que verificou ocorrência de flores nos ramos plagiotrópicos marcados, encerrando precocemente 0 período de emissão de flores, visto que, nos outros anos houve ocorrência de floradas nos meses de novembro e dezembro.

Conforme dados apresentados na Figura 1/2009 a precipitação pluvial iniciou antecipadamente no ano em análise, com volumes consideráveis de precipitações no final de agosto e inicio de setembro, apresentando um acumulado de 30,5 e 49,5 $\mathrm{mm}$ respectivamente.

Esses volumes de precipitações ocorridos até o dia 10/09/2009, fez com que não houvesse restrições hídricas às plantas, desencadeando o processo de quebra de dormência dos botões florais culminado na abertura floral do dia 14/09/2009 (Figura 2/2009).

A maior floração ocorreu nas avaliações do dia 2 e 5 de outubro/2009, representando $67,68,52,57,59 \%$ para os tratamentos A, B. C, D e E respectivamente. Essa floração pode ter sido decorrência de uma queda de temperatura entre os dias 22 a 27 de setembro/2009, variando entre 15 e $17^{\circ}$ C na média diária. Nascimento et al. (2008), em estudo de eventos do florescimento do cafeeiro em resposta a elementos meteorológicos, concluíram que alterações morfológicas da gema ocorrem após um período de déficit hídrico, seguido de precipitação e menor amplitude térmica.

A última floração ocorreu na avaliação do dia 18/11/2009 e, em decorrência de volumes constantes de precipitações ocorridos desde início de outubro, não houve influência dos tratamentos de irrigação.

\subsection{Flores, frutos e porcentagem de vingamento das flores}

Através da análise de variância das características reprodutivas do cafeeiro, observou-se diferença significativa para "número de flores emitidas, número de frutos e média da \% vingamento das flores" (Tabela $1)$.

Observou-se que o comportamento das floradas nos períodos considerados (2006, 2007, 2008 e 2009) foi de manter a bienalidade do cafeeiro, com maior número de flores e de frutos nos anos de 2006 e 2008. A avaliação de floração do ano de 2006, representa a segunda florada da lavoura após recepa, sendo que essa emissão de flores proporcionou um ano de carga alta, apesar de não ter sido antecedida por um ano de carga baixa, pois antecedente a essa florada a planta 
de café se encontrava em pleno desenvolvimento vegetativo, aumentando o número e o comprimento de seus ramos plagiotrópicos e o número de gemas reprodutivas. A florada 2007 refletiu em um ano de baixa produtividade, seguido da avaliação de 2008 que apresentou a maior emissão de flores, que acarretou uma alta produção. Pode-se observar na Tabela 1 que a variável "flores" apresentou-se com diferença significativa nos anos de 2008 e 2009, para manejo de irrigação, mostrando que no ano 2008 os tratamentos A (sem irrigação) e C, apresentaram maior número de flores quando comparado aos demais tratamentos, que não diferiram entre si. No ano de 2009, apenas o tratamento A demonstrou ser estatisticamente superior no número de flores emitidas, diferindo dos tratamentos irrigados.

TABELA 1 - Valores do número total de flores, de frutos e da porcentagem de vingamento de flores de cada tratamento de irrigação, nos anos de 2006, 2007, 2008 e 2009, e os valores do coeficiente de variação (CV \%) da análise estatística realizada. UFLA, Lavras-MG/ 2011.

\begin{tabular}{|c|c|c|c|c|}
\hline \multirow{2}{*}{$\begin{array}{l}\text { Manejo de } \\
\text { Irrigação } \\
\end{array}$} & \multicolumn{4}{|c|}{ Flores** } \\
\hline & 2006 & 2007 & 2008 & 2009 \\
\hline $\bar{A}$ & 943 & 109 & $1594 \mathrm{a}$ & $209 \mathrm{a}$ \\
\hline $\mathrm{B}$ & 345 & 52 & $327 \mathrm{~b}$ & $74 \mathrm{~b}$ \\
\hline $\mathrm{C}$ & 344 & 49 & $1105 \mathrm{a}$ & $77 \mathrm{~b}$ \\
\hline $\mathrm{D}$ & 470 & 110 & $981 \mathrm{~b}$ & $76 \mathrm{~b}$ \\
\hline $\mathrm{E}$ & 369 & 19 & $428 \mathrm{~b}$ & $38 \mathrm{~b}$ \\
\hline \multirow[t]{3}{*}{$\mathrm{CV}(\%)$} & 71,41 & 90,44 & 46,33 & 58,06 \\
\hline & \multicolumn{4}{|c|}{ Frutos** } \\
\hline & 2006 & 2007 & 2008 & 2009 \\
\hline A & 407 & 13 & $849 \mathrm{a}$ & $118 \mathrm{a}$ \\
\hline B & 187 & 26 & $250 \mathrm{~b}$ & $39 \mathrm{~b}$ \\
\hline $\mathrm{C}$ & 211 & 25 & 942 a & $53 \mathrm{~b}$ \\
\hline $\mathrm{D}$ & 287 & 60 & $800 \mathrm{a}$ & $43 \mathrm{~b}$ \\
\hline $\mathrm{E}$ & 202 & 10 & $370 \mathrm{~b}$ & $30 \mathrm{~b}$ \\
\hline \multirow[t]{3}{*}{$\mathrm{CV}(\%)$} & 89,91 & 98,21 & 40,77 & 54,09 \\
\hline & \multicolumn{4}{|c|}{ \% Vingamento $* *$} \\
\hline & 2006 & 2007 & 2008 & 2009 \\
\hline A & 39 & $22 \mathrm{~b}$ & $59 \mathrm{~b}$ & 61 \\
\hline B & 56 & $58 \mathrm{a}$ & $77 \mathrm{a}$ & 58 \\
\hline $\mathrm{C}$ & 61 & $61 \mathrm{a}$ & $85 \mathrm{a}$ & 76 \\
\hline $\mathrm{D}$ & 60 & $54 \mathrm{a}$ & $84 \mathrm{a}$ & 53 \\
\hline $\mathrm{E}$ & 42 & $54 \mathrm{a}$ & $86 a$ & 79 \\
\hline $\mathrm{CV}(\%)$ & 42,22 & 20,96 & 15,43 & 37,55 \\
\hline
\end{tabular}

** Média seguidas por letras diferentes na vertical e na horizontal, diferem entre si pelo teste de Scott-Knott (5\%)

Fonte: Próprio autor.

A análise estatística mostrou uma diferença quanto ao "número de frutos", no ano de 2008, destacaram-se com maior número de frutos os tratamentos $\mathrm{A}, \mathrm{C}$ e $\mathrm{D}$, e 
no ano de 2009 o tratamento A se mostrou estatisticamente com maior número de frutos que os demais tratamentos irrigados que não diferiram entre si. Foi comentado anteriormente que o tratamento A teve uma proporção no número de flores emitidas superior aos demais tratamentos, o mesmo aconteceu em relação ao número de frutos, mas numa amplitude menor.

Essa diminuição na proporção de flores para frutos emitidos no tratamento A, é conseqüência desse tratamento ter apresentado estatisticamente uma menor "porcentagem de vingamento de flores", quando comparado aos demais tratamentos irrigados, nos anos de 2007 e 2008 (Tabela 1).

\subsection{Produtividade}

$\mathrm{Na}$ análise de variância da produção do cafeeiro, observou-se diferença significativa para os tratamentos de irrigação (Tabela 2). Observou-se que o comportamento da produção nos períodos considerados (2006, 2007, 2008, 2009 e 2010) foi de manter a bienalidade do cafeeiro, apresentando bienalidade positiva em 2007 e 2009, e anos de baixas produções (bienalidade negativa) nos anos de 2008 e 2010 conforme Tabela 2. A produção de 2006 apresentou-se menor quando comparada à produção de 2007, porém considerada uma boa produção, por se tratar da primeira produção após recepa do cafeeiro. Na produção de 2007 a planta já se apresentava em estágio de pouco desenvolvimento vegetativo (planta adulta), tendo um ano de alta produção, seguido em 2008 por uma baixa produção, evidenciando a bienalidade dos cafeeiros. Aliado ao estudo do fenômeno da floração, Guerra et al. (2007) enfocam também sobre $\mathrm{o}$ fenômeno da bienalidade que tem sido mais acentuada nas lavouras irrigadas.

Analisando os manejos de irrigação dentro de cada safra, o efeito significativo para manejo de irrigação apresentou-se nos anos de 2007, 2009 e 2010 (Tabela 2). No ano 2007, os tratamentos B e E estatisticamente apresentaram maior produção em relação aos demais tratamentos que não diferiram entre si. Já no ano 2009, os tratamentos B e E permaneceram com maior produção, acrescentando a esse grupo o tratamento C, que estatisticamente foram iguais. Rezende et al. (2006), avaliando lâminas de irrigação em lavoura cafeeira recepada, cultivar Topázio MG-1190, aos 65 meses após plantio, verificaram que com a prática da irrigação, houve aumentos de produtividade do cafeeiro, contribuindo para melhorar o rendimento da lavoura e retardando a maturação dos frutos. Silva e Reis (2007), avaliando o efeito de diferentes épocas de irrigação e parcelamento de adubação sobre indicadores fisiológicos associados à produtividade do cafeeiro, cultivar Catuaí Vermelho, IAC 144 (18 anos de idade e espaçamento $3,5 \mathrm{~m} \mathrm{x} 0,8 \mathrm{~m}$ ), observaram que em relação à produtividade a 
irrigação realizada entre 01/06 e 30/09 apresentou o melhor resultado, com valor médio de 76,95 sacas $a^{-1}$. Relatos de padrão superior de crescimento (CARVALHO et al. 2006; SCALCO et al. 2009), e aumentos consideráveis de produtividade em lavouras irrigadas sob diferentes sistemas e manejos ainda podem ser encontrados em relatos de Alexandre et al. (2008); Scalco et al. (2008); Scalco et al. (2009); Assis et al. (2009); Arantes, Faria e Resende (2009).

TABELA 2 - Produção de cada tratamento de irrigação nos anos de 2006, 2007, 2008, 2009, 2010 e acumulada (5 anos), com seus coeficientes de variação $(\mathrm{CV} \%)$ e porcentagem relativa em relação ao tratamento sem irrigação (testemunha). UFLA, Lavras-MG/ 2011.

\begin{tabular}{lllllll}
\hline ANOS & CV(\%) & A & B & C & D & E \\
\hline $\mathbf{2 0 0 6}$ & 21,9 & 32,5 & 23,3 & 28,5 & 24,8 & 22,5 \\
$\mathbf{2 0 0 7}$ & 19,7 & $65,3 \mathrm{~b}$ & $82,5 \mathrm{a}$ & $70,5 \mathrm{~b}$ & $72,0 \mathrm{~b}$ & $87,0 \mathrm{a}$ \\
$\mathbf{2 0 0 8}$ & 71,4 & 1,9 & 4,9 & 3,2 & 4,2 & 2,5 \\
$\mathbf{2 0 0 9}$ & 13,1 & $88,5 \mathrm{~b}$ & $121,0 \mathrm{a}$ & $124,8 \mathrm{a}$ & $95,5 \mathrm{~b}$ & $115,0 \mathrm{a}$ \\
$\mathbf{2 0 1 0}$ & 40,6 & $42,3 \mathrm{a}$ & $17,5 \mathrm{~b}$ & $17,8 \mathrm{~b}$ & $14,0 \mathrm{~b}$ & $11,3 \mathrm{~b}$ \\
Acumulado & 11,2 & 230,5 & 249,8 & 245,0 & 210,3 & 238,0 \\
\hline Relativa(\%) & & $\mathbf{1 0 0}$ & $\mathbf{1 0 8 , 4}$ & $\mathbf{1 0 6 , 3}$ & $\mathbf{9 1 , 2}$ & $\mathbf{1 0 3 , 3}$ \\
\hline
\end{tabular}

*Média seguidas por letras diferentes na horizontal, diferem entre si pelo teste de Scott-Knott (5\%)

Fonte: Próprio autor.

Em 2010, o tratamento A (sem irrigação) se destacou apresentando maior produção, diferindo estatisticamente dos tratamentos irrigados. Essa maior produção do tratamento A pode ter sido influenciada por um menor desgaste das plantas no ano anterior, diminuindo a amplitude da bienalidade do cafeeiro, que foi acentuada em plantas irrigadas. Esse fato tornou todos os tratamentos estatisticamente iguais nas produções acumuladas dos 5 anos analisados. Lima, Custodio e Gama (2008), encontraram resultados parecidos onde estudaram, por cinco safras, a produtividade do cafeeiro e o rendimento do café irrigado por pivô central em Lavras, MG. Os autores discutem que uma menor intensidade de déficit hídrico pode ter contribuído para elevada produtividade das plantas não irrigadas durante a quarta safra, igualando esse tratamento aos irrigados.

\section{CONCLUSÕES}

Os tratamentos de irrigação não proporcionaram um sincronismo diferenciado na floração do cafeeiro. A umidade do solo foi o fator meteorológico limitante da quebra de dormência dos botões florais no tratamento sem irrigação. A queda de temperatura parece ter sido a principal responsável pela quebra de dormência dos botões florais nos tratamentos irrigados. 
Somente a irrigação não foi capaz de minimizar a bienalidade de produção do cafeeiro, sendo mais intensificada nos tratamentos irrigados.

\section{REFERÊNCIAS BIBLIOGRÁFICAS}

ALEXANDRE, L.P.B.; SCALCO, M. S.; GUIMARÃES, R. J.; ASSIS, G. A. Características produtivas do cafeeiro em plantio superadensado e convencional sob sistema diferenciado da irrigação - Quinta Safra. In: SIMPÓSIO BRASILEIRO DE PESQUISA EM CAFEICULTURA IRRIGADA, 10, Araguari, 2008. Anais.... Araguari: ACA, p. 206-209, 2008.

ARANTES, K. R.; FARIA, M. A. de; REZENDE, F. C. Recuperação do cafeeiro (Coffea arabica L.) após recepa, submetido a diferentes lâminas de água e parcelamentos da adubação. Acta Scientiarum (UEM), v. 31, p. 313-319, 2009.

ASSIS, G. A.; GUIMARÃES, R. J. ; SCALCO, M. S. ; SOBREIRA, F. M. ; FIDELIS, I. . Padrões de rendimento do cafeeiro em função do regime hídrico, densidade de plantio e bienalidade de produção. In: XI SIMPÓSIO BRASILEIRO DE PESQUISA EM CAFEICULTURA IRRIGADA, 11, Araguari, 2009. Anais... Uberaba: ACA/UNIUBE, 2009.

BOMFIM NETO, H.; MANTOVANI, E. C.; DAMATTA, F. M.; COSTA, L. C.; FREIAS A. dos R.; PEREIRA, B. L. Uso do déficit hídrico como ferramenta para uniformizar a floração do cafeeiro no cerrado de Minas Gerais. In: SIMPÓSIO BRASILEIRO DE PESQUISA EM CAFEICULTURA IRRIGADA, 9., 2007, Araguari. Anais... Araguari: UFU, 2007 b. p. 133-136.

CARVALHO, C. H. M. de; COLOMBO. A.; SCALCO, M. S; MORAIS, A. R. de Evolução do crescimento do cafeeiro (coffea
A influencia positiva da irrigação na produtividade do cafeeiro se manifestou nos anos de alta produtividade.

arabica l.) irrigado e não irrigado em duas densidades de plantio. Ciência e

Agrotecnologia, Lavras, v. 30, n. 2, p. 243250, mar./abr., 2006.

DANTAS, A. A. A., Carvalho, L. G. de e Ferreira, E. Classificação e tendências climáticas em Lavras, MG. Ciência e agrotecnologia, Dez 2007, vol.31, no.6, p.1862-1866. ISSN 1413-7054

GUERRA, A. F.; ROCHA, O. C.; RODRIGUES, G. C.; SANZONOWICZ, C.; FILHO, G. C. R.; TOLEDO, P. M. dos R. Sistema de produção de café irrigado: um novo enfoque. Item, ABID: Brasília, n. 63, p. 52-61, 2007.

LIMA, L. A.; CUSTÓDIO, A. A. de P.; GOMES, N. M. Produtividade e rendimento do cafeeiro nas cinco primeiras safras irrigado por pivô central em Lavras, MG. Ciência e Agrotecnologia. Lavras, v.32, n. 6, p. 18321842, nov./dez., 2008.

MATIELlO, J. B. 34 Congresso Brasileiro de Pesquisas Cafeeiras, Caxambu- MG, p. 37-65, 2008, 408p.

MATIELLO, A. W. R. Estresso ou não meu cafezal. Revista brasileira de tecnologia cafeeira: Coffea, Varginha-MG, III, $n^{\circ} 10$, p. 29-30, 2006.

NASCIMENTO, M. N. do; ALVES, J. D.; SOARES, A. M.; CASTRO, E. M. de; MAGALHÃES, M. M.; ALVARENGA, A. A. de; SILVA, G. H. Alterações bioquímicas de plantas e morfológicas de gemas de cafeeiro associadas a eventos do florescimento em resposta a elementos meteorológicos. Ciência Rural, Santa Maria, v. 38, n. 5, p. 1300-1307, ago. 2008. 
REZENDE, F. C.; OLIVEIRA, S. dos R.;

FARIA, M. A. de; ARANTES, K. R.

Características produtivas do cafeeiro (Coffea

arabica L. cv., Topázio MG -1190), recepado

e irrigado por gotejamento. Coffea Science,

Lavras, v. 1, n. 2, p. 103-110, jul./dez. 2006.

SANTINATO, R.; FERNANDES, A. L. T.; FERNANDES, D. R.; Irrigação na cultura

do café; $O$ lutador, $2^{\mathrm{a} e d}$.; Belo Horizonte MG, 2008, 476p.

SCALCO, M.S.; ALEXANDRE, L. P.; MIRANDA, W. L.; ALVARENGA, L. A.; ASSIS, G. A. Padrão de crescimento de cafeeiros podados, irrigados e não irrigados em duas densidades de plantio. In:

CONGRESSO BRASILEIRO DE

ENGENHARIA AGRÍCOLA, 38. 2009, Juazeiro - BA, Petrolina - PE, Anais... Jaboticabal: SBEA, 2009. (CD-ROM).

SCALCO, M. S.; COLOMBO, A.; GUIMARÃES, R. J.; SILVA, P. M. de O. ; ALEXANDRE, L.P.B. . Produtividade do cafeeiro em função do regime hídrico e do adensamento. In: SIMPÓSIO BRASILEIRO DE PESQUISA EM CAFEICULTURA IRRIGADA, 10, 2008, Araguari. 2008, Anais... Araguari: ACA, 2008. p. 94-99.

SILVA, J. G. F.; REIS, E. F. dos. Irrigação do cafeeiro Conilon, In: FERRÃO, R. G.; FONSECA, A. F. A. da; BRAGANÇA, S. M.; FERRÃO, M. A. G.; MUNER, L. H. De, Café Conilon,Vitória, ES: Incaper, 2007. 